\title{
Characterization of the initial complaint and care pathways prior to diagnosis in very young sporadic Alzheimer's disease
}

\author{
Pauline Olivieri ${ }^{1,2,3^{*}+}$ (D), Lorraine Hamelin ${ }^{1,2,3+}$, Julien Lagarde ${ }^{1,2,3}$, Valérie Hahn ${ }^{1}$, Elodie Guichart-Gomez ${ }^{1}$, \\ Carole Roué-Jagot ${ }^{1}$ and Marie Sarazin ${ }^{1,2,3}$
}

\begin{abstract}
Background: Very-early-onset Alzheimer's disease (young-AD) differentiates from late-onset AD (old-AD) by a predominant involvement of the parietal neocortex leading to atypical presentations. The diagnosis of AD is often not the first to be mentioned in such young patients.

Methods: We retrospectively reviewed the initial complaint and care pathways of 66 sporadic young-AD (age <62) and 30 old-AD patients (age > 65) and compared their neuropsychological profiles at the time of diagnosis (based on clinical-biological criteria) with 44 amyloid-negative controls.

Results: The initial complaint of young-AD was non-cognitive and mimicked a burnout in $32 \%$ of cases. Their main cognitive complaints were memory ( $38 \%$ vs $87 \%$ in old-AD) and language (17\% vs 13\%) impairment. The referral to a psychiatrist prior to $A D$ diagnosis was more frequent in young-AD than in old-AD ( $26 \%$ vs $0 \%$ ). At the time of diagnosis, young-AD were at a more severe stage of dementia than old-AD $(24 \%$ vs $10 \%$ with $C D R \geq 1)$ but had less anosognosia.
\end{abstract}

Conclusions: Better identifying the initial signs of very-early-onset AD is crucial to improve the early diagnosis and develop new treatments.

Keywords: Young-Alzheimer's disease, Initial complaint, Diagnosis

\section{Background}

Two main clinical features differentiate early-onset Alzheimer's disease (young-AD) from late-onset AD (old$\mathrm{AD})$ : the frequency of atypical phenotypes and the rapidity of clinical decline. Aside from the common typical amnestic presentation, young-AD patients have more often than older $\mathrm{AD}$ patients an atypical non-amnestic syndrome with executive, language, or visuo-spatial dysfunction [1, 2]. These phenotypic variants are explained by the

\footnotetext{
* Correspondence: p.olivieri@ghu-paris.fr; paulineolivieri@hotmail.fr

†Pauline Olivieri and Lorraine Hamelin contributed equally to this work. 'Department of Neurology of Memory and Language, GHU Paris Psychiatry and Neurosciences, Hôpital Sainte Anne, 1 rue Cabanis, F-75014 Paris, France 2Université de Paris, F-75006 Paris, France

Full list of author information is available at the end of the article
}

location of the cortical damage: in young-AD, the lesions predominantly affect the temporo-parietal cortices with a relative sparing of the hippocampi, whereas in old- $\mathrm{AD}$, a greater medial temporal lobe atrophy is observed, leading to severe amnesia [3-5]. In patients with an atypical nonamnestic presentation, the diagnosis of $\mathrm{AD}$ is possible by using pathophysiological biomarkers such as cerebrospinal fluid (CSF) biomarkers or amyloid/tau positron emission tomography (PET) imaging.

Age also plays a role in the rapidity of the clinical progression, the rate of cognitive decline being higher in young than in older AD patients, suggesting a more aggressive disease [1].

C C The Author(s). 2021 Open Access This article is licensed under a Creative Commons Attribution 4.0 International License, which permits use, sharing, adaptation, distribution and reproduction in any medium or format, as long as you give appropriate credit to the original author(s) and the source, provide a link to the Creative Commons licence, and indicate if changes were made. The images or other third party material in this article are included in the article's Creative Commons licence, unless indicated otherwise in a credit line to the material. If material is not included in the article's Creative Commons licence and your intended use is not permitted by statutory regulation or exceeds the permitted use, you will need to obtain permission directly from the copyright holder. To view a copy of this licence, visit http://creativecommons.org/licenses/by/4.0/ The Creative Commons Public Domain Dedication waiver (http://creativecommons.org/publicdomain/zero/1.0/) applies to the data made available in this article, unless otherwise stated in a credit line to the data. 
The atypical phenotypes in young subjects lead to a delayed diagnosis of young-AD [1]. Combined with the rapid progression of cognitive dysfunction make it more difficult to include these patients in therapeutic trials, as their symptoms are often too pronounced at the time of diagnosis.

Little is known about the initial complaint of young$\mathrm{AD}$, particularly for patients who still have a professional activity. This information is however of utmost importance to better detect the earliest signs of the disease.

In the present study, we aimed to retrospectively characterize the initial complaint (at the time of the first symptoms) and the care pathways of young-AD patients with or without professional activity, and to compare their neuropsychological profiles at diagnosis with those of old-AD patients. We hypothesized that beyond the purely cognitive complaint affecting memory or language, which is usually reported in old-AD, atypical initial complaints could be identified in young-AD patients, especially in the workplace.

\section{Methods}

\section{Study design and population}

We retrospectively reviewed the files of all patients younger than 62 referred to the Department of Neurology of Memory and Language at Sainte Anne Hospital in Paris from January 2017 to March $2020(n=247)$ (Fig. 1). Among them, 66 patients had a diagnosis of AD based on clinical and biological criteria defined by the CSF AD biomarker profile. We have chosen the age of 62 years, in order to target patients likely to be in active employment, as 62 is the legal age for retirement in France. In addition, 30 old-AD patients with a clinicalbiological diagnosis (CSF AD biomarker profile) and a group of 44 controls (16 younger than 62 and 28 older controls) with a negative PiB-PET imaging were included. In addition, $15 \mathrm{AD}$ patients (2 young-AD and 13 old-AD) had a PiB-PET imaging, which was positive in all cases.

Two neurologists, blind to each other, collected retrospectively in the medical file the main initial complaints of all patients, which were classified as (1) cognitive including language, memory, visuospatial dysfunction, or behavioral disturbances or (2) occupational burnout diagnosis according to the World Health Organization ICD11 definition [6]. They also collected their care pathways before they were referred to our department. When there was more than one complaint, the instruction was to consider as the main complaint the one leading to the neurological consultation and being at the forefront of the interview with the patient and his/her caregiver. For all types of complaints other than behavioral, the

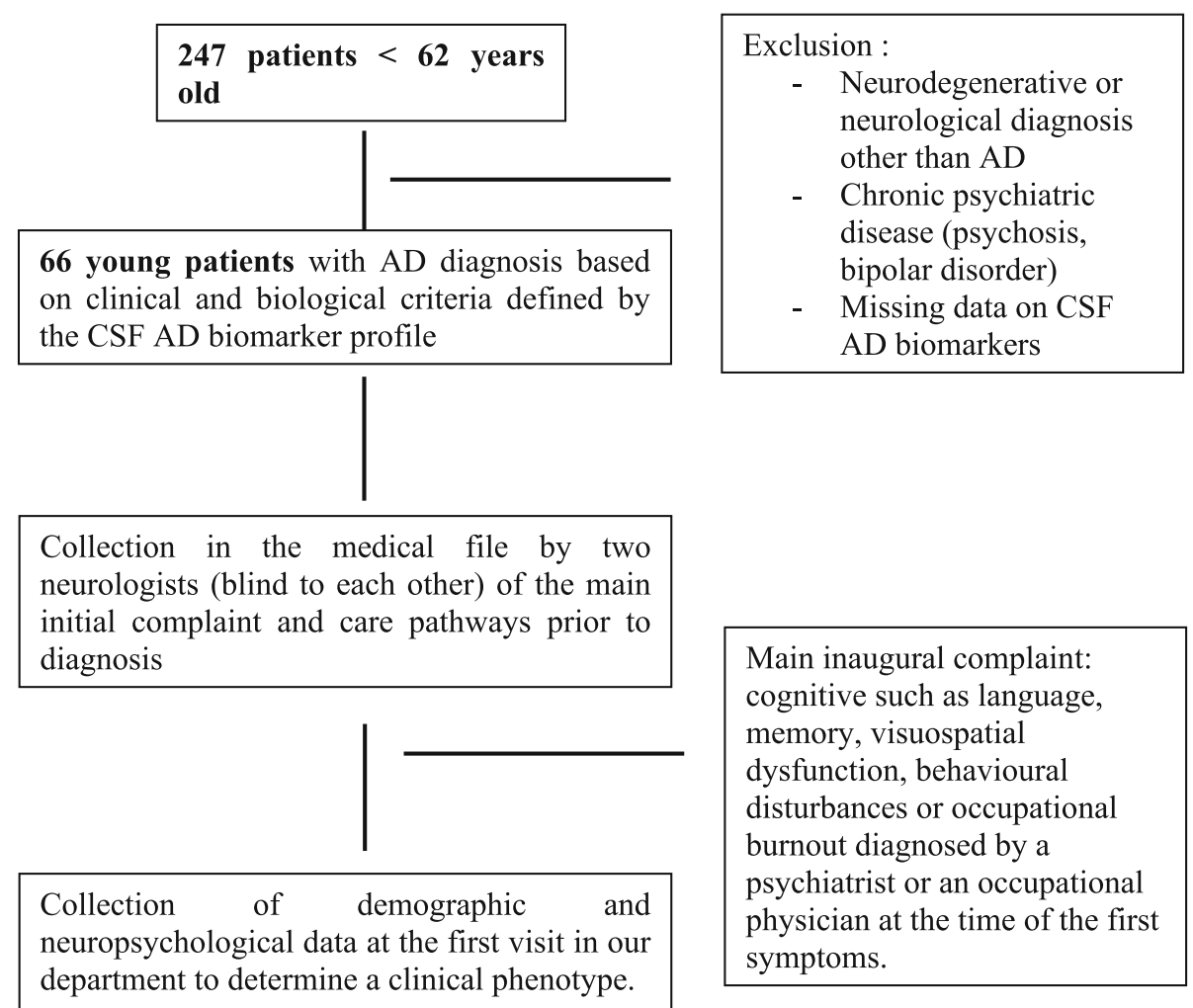

Fig. 1 Identification of the initial symptoms and care pathways in very-young AD patients 
patient's and the caregiver's statements were concordant. For behavioral complaints, which could be more subjective, we only considered the impression of the caregiver. The diagnosis of occupational burnout syndrome was made by a psychiatrist or an occupational physician, at the time of the first symptoms, before the patient was referred to our department [6]. It was characterized by a feeling of reduced professional efficacy and energy depletion or exhaustion, leading to a severe anxiety, in the absence of cognitive neurological symptoms [6]. The diagnosis of burnout was retained when no other neurological cognitive disorder was reported by the patient, family, or the psychiatrist or occupational physician. All patients performed the same neuropsychological battery at the time of diagnosis. In addition, we assessed social life changes and cognitive (memory) anosognosia by the Cambridge Behavioural Inventory Revised Scale (CBI-R) [7] and the Mc Nair scale, which were filled both by the patients and their caregiver.

All controls provided written informed consent as part of ongoing research protocols (Imabio3 and Shatau7Imatau studies). In accordance with the French legislation, patients for whom clinical and CSF data were generated during routine clinical workup and their relatives were informed that individual data could be used in clinical research studies and they signed a specific consent form (MA-D20-R56 study).

\section{Statistical analysis}

All statistical analyses were performed with $\mathrm{SPSS}^{\circ} 26.0$ (SPSS Inc., Chicago, IL, USA). A chi-square or Fisher's exact test was performed for group comparisons of categorical data. A rank sum test or $t$-test was used for analyses of continuous variables. The results of quantitative variables are presented as means \pm standard deviations (SD). For dichotomous variables, numbers and calculated percentages are presented. $P$-values $<0.05$ were considered statistically significant.

\section{Results}

Initial complaint and care pathways before diagnosis (Table 1)

The initial complaint of young-AD patients was memory (38\%), language (17\%), visuo-spatial $(6 \%)$, or behavioral (7\%) impairment. In $32 \%$ of young-AD patients, the initial complaint was an occupational burnout-like syndrome. The diagnosis of burnout was made by a psychiatrist or an occupational physician for $80 \%$ of these cases, in the absence of overt language, memory,

Table 1 Inaugural complaint and cognitive phenotype at diagnosis in young and old-AD patients

\begin{tabular}{|c|c|c|c|c|c|c|c|c|c|c|c|}
\hline \multicolumn{3}{|c|}{ Inaugural complaint (IC) } & $\begin{array}{c}\text { Delay } \\
\text { between IC } \\
\text { and diagnosis }\end{array}$ & \multicolumn{8}{|c|}{$\begin{array}{l}\text { Cognitive presentation at the time of diagnosis according to the early } \\
\text { complaint* after inaugural complaint }\end{array}$} \\
\hline & $\begin{array}{l}\text { Young- } \\
\text { AD } \\
n=66\end{array}$ & $\begin{array}{l}\text { Old- } \\
\text { AD } \\
n=30\end{array}$ & $\begin{array}{cc}\begin{array}{c}\text { Young- } \\
\text { AD }\end{array} & \text { Old- } \\
\text { AD } \\
2.5 & 2.6 \\
\text { years } & \text { years }\end{array}$ & $\begin{array}{l}\text { Young- } \\
\text { AD } \\
\quad \text { Lin }\end{array}$ & $\begin{array}{l}\text { Old- } \\
\mathrm{AD} \\
\text { ic }\end{array}$ & $\begin{array}{l}\text { Youn } \\
\text { g-AD } \\
\text { Cort } \\
\text { (bipar }\end{array}$ & $\begin{array}{l}\text { Old- } \\
\text { AD } \\
\text { cal } \\
\text { etal) }\end{array}$ & $\begin{array}{l}\text { Young- } \\
\text { AD } \\
\text { Logo } \\
\text { aph }\end{array}$ & $\begin{array}{l}\text { Old- } \\
\text { AD } \\
\text { ic } \\
\text { ia }\end{array}$ & $\begin{array}{l}\text { Young- } \\
\mathrm{AD} \\
\text { Visuo- }\end{array}$ & $\begin{array}{l}\text { Old- } \\
\text { AD } \\
\text { atial }\end{array}$ \\
\hline $\begin{array}{l}\text { Burn out } \\
\text { (without } \\
\text { any specific } \\
\text { cognitive } \\
\text { complaint) }\end{array}$ & $\begin{array}{c}32 \% \\
(n=21)\end{array}$ & $0 \%$ & & $\begin{array}{l}20 \% \\
(n=4)\end{array}$ & NA & $\begin{array}{c}55 \% \\
(\mathrm{n}=11)\end{array}$ & NA & $\begin{array}{l}5 \% \\
(n=1)\end{array}$ & NA & $\begin{array}{l}20 \% \\
(n=4)\end{array}$ & NA \\
\hline Memory & $\begin{array}{c}38 \% \\
(n=26)\end{array}$ & $\begin{array}{l}87 \% \\
(n=26)\end{array}$ & & $\begin{array}{l}30 \% \\
(\mathrm{n}=7)\end{array}$ & $\begin{array}{c}88 \% \\
(\mathrm{n}=23) \\
\end{array}$ & $\begin{array}{c}65 \% \\
(n=15) \\
\end{array}$ & $\begin{array}{l}12 \% \\
(\mathrm{n}=3)\end{array}$ & $\begin{array}{l}5 \% \\
(n=1)\end{array}$ & $0 \%$ & $0 \%$ & $0 \%$ \\
\hline Langage & $\begin{array}{c}17 \% \\
(n=11)\end{array}$ & $\begin{array}{l}13 \% \\
(n=4)\end{array}$ & & $0 \%$ & $\begin{array}{l}25 \% \\
(n=1)\end{array}$ & $\begin{array}{l}45 \% \\
(n=5)\end{array}$ & $0 \%$ & $\begin{array}{l}55 \% \\
(n=6)\end{array}$ & $\begin{array}{l}75 \% \\
(n=3)\end{array}$ & $0 \%$ & $0 \%$ \\
\hline Visuospatial & $\begin{array}{c}6 \% \\
(n=3)\end{array}$ & $0 \%$ & & $0 \%$ & $0 \%$ & $\begin{array}{l}67 \% \\
(\mathrm{n}=2)\end{array}$ & $0 \%$ & $0 \%$ & $0 \%$ & $\begin{array}{l}33 \% \\
(n=1)\end{array}$ & $0 \%$ \\
\hline Behavioural & $\begin{array}{c}7 \% \\
(n=5)\end{array}$ & $0 \%$ & & $0 \%$ & $0 \%$ & $100 \%$ & $0 \%$ & $0 \%$ & $0 \%$ & $0 \%$ & $0 \%$ \\
\hline
\end{tabular}

*Data available for 61 patients with young-AD

Four cognitive presentations have been identified from the results of the neuropsychological assessments:

-Limbic characterized by hippocampal amnestic syndrome, [8]

-Biparietal dysfunction characterized by a visuospatial deficit, dyspraxia, dysgraphia, logopenic aphasia, and deficit of auditory-verbal short-term memory [2, 9]

-Logopenic variant primary progressive aphasia according to the clinical criteria of Gorno-Tempini et al. 2011 [10].

-Visual spatial dysfunction, known as posterior cortical atrophy (PCA) or "Benson's disease" characterized by oculomotor apraxia, optic ataxia, dressing apraxia, environmental disorientation, abnormal anti-saccades, neglect, constructional difficulty, simultanagnosia, visual agnosia, and prosopagnosia [11, 12]. 
gestural, visuo-spatial, neurological behavioral disorders or even other neurological signs. For these patients, families did not report any specific cognitive symptom. In the sub-group of young-AD patients having a professional activity $(n=46)$, burnout was the initial complaint in $46 \%$ of cases. In the old-AD patients, the initial complaints were mainly memory $(87 \%)$ and language (13\%) impairment. Fifty-two percent of young-AD patients with a burnout syndrome were initially referred to a psychiatrist (vs 13\% of the young-AD patients with an initial cognitive complaint) and $28 \%$ to an occupational physician.

\section{Cognitive phenotype and neuropsychological evaluation at the time of diagnosis}

The diagnosis was made more than 2 years after the first reported complaint. A phenotype of cognitive biparietal dysfunction (visuospatial deficit, dyspraxia, dysgraphia, logopenic aphasia and deficit of auditory-verbal short term memory $[2,9])$ was the most common, observed in $55 \%$ and $64 \%$ of young-AD patients with and without burnout (see Table 1). The comparisons of the neuropsychological scores between young-AD, old-AD, and, respectively, young and old controls are detailed in Table 2. Young-AD patients presented with a more severe cognitive impairment, a greater loss of autonomy assessed by the Clinical Dementia Rating (CDR) scale ( $40 \%$ of young-AD patients had a CDR $\geq 1$ versus $10 \%$ in old-AD patients), and less anosognosia compared to oldAD. No clinical or neuropsychological difference was observed between young-AD with and without an initial burnout, except for educational level, which tended to be higher in the former (Table 2).

\section{Discussion}

Young-AD is the most common early-onset neurodegenerative disease and presents less commonly with memory deficits and more frequently with focal cortical dysfunction, which makes the diagnosis challenging. In our cohort, $68 \%$ of the young-AD patients (younger than 62 years) had a purely cognitive initial complaint and were referred primarily to a neurologist. Interestingly, in a third of our young-AD patients, the initial complaint was atypical and led to the initial diagnosis of a burnout syndrome. Among the young-AD patients with a professional activity $(70 \%)$, a burnout-like syndrome was the first diagnosis in almost half of the cases. These patients had an inability to carry out concurrent professional tasks, leading to a reduction of professional efficacy and a severe anxiety, in the absence of overt language, memory, gestural, visuo-spatial disorders, or other neurological signs. They were conscious of their difficulties and tried to compensate, which led to work overload, mental exhaustion, and personal depreciation. Their relatives did not report any specific cognitive abnormality. Most of these patients were treated by a psychiatrist during several months, before being referred to a neurologist. It is crucial to detect this type of situation as early as possible, in order to offer the most appropriate care, such as specific medication, rehabilitation, and adaptation of the workspace when possible, and also to avoid the prescription of contraindicated treatment such as anticholinergic antidepressants.

As expected, in old-AD patients, the initial complaint was about memory $(87 \%)$, or language, with a lack of words (13\%).

The time between the first symptoms and the first neuropsychological assessment was more than 2 years, without any significant difference between old-AD and young-AD. A greater delay of diagnosis in young- $A D$ than old-AD has however been reported previously, [13] but could not be attributed to anosognosia, which is less pronounced in young-AD patients.

Young-AD presented with a more severe cognitive impairment at diagnosis compared to old-AD, especially with regard to instrumental functions (language, gestural praxis, visuo-spatial abilities), and working memory, resulting in a greater loss of autonomy and lower MMSE scores.

Compared to old-AD, neuroimaging studies showed that young-AD patients may have a relative preservation of hippocampal volume and a predominant parietal atrophy, $[3,4]$ with a more severe parietal hypometabolism, [14] which is congruent with a greater percentage of atypical presentations in these young patients. The extent and distribution of tau pathology measured by PET also differed between young-AD and old-AD, with tau aggregation in widespread neocortical regions (prefrontal and parietal cortex) in young-AD while the pattern of tau deposition was more confined to the temporal regions in old-AD [5].

Burnout-like syndrome could be due to an early alteration of the fronto-parietal connectivity. MRI studies suggest that functional connectivity changes differ in young- $\mathrm{AD}$ and old- $\mathrm{AD}$, young- $\mathrm{AD}$ being mainly driven by an early involvement of fronto-parietal networks [15]. Fronto-parietal circuit alterations contribute to impairments in central executive network, top-down attentional control, and working memory [16]. Progressive changes of neural networks are present before neuronal loss and regional atrophy [17] and could contribute to the occurrence of burnout-like syndromes before the onset of more classic cortical cognitive signs. The hypotheses regarding the anatomical underpinnings of the burnout-like syndrome in these patients will need to be tested in dedicated studies including imaging data. 
Table 2 Neuropsychological assessment in young-AD presenting with and without an initial burnout like syndrome (BO), old-AD, young and old controls (YC, OC)

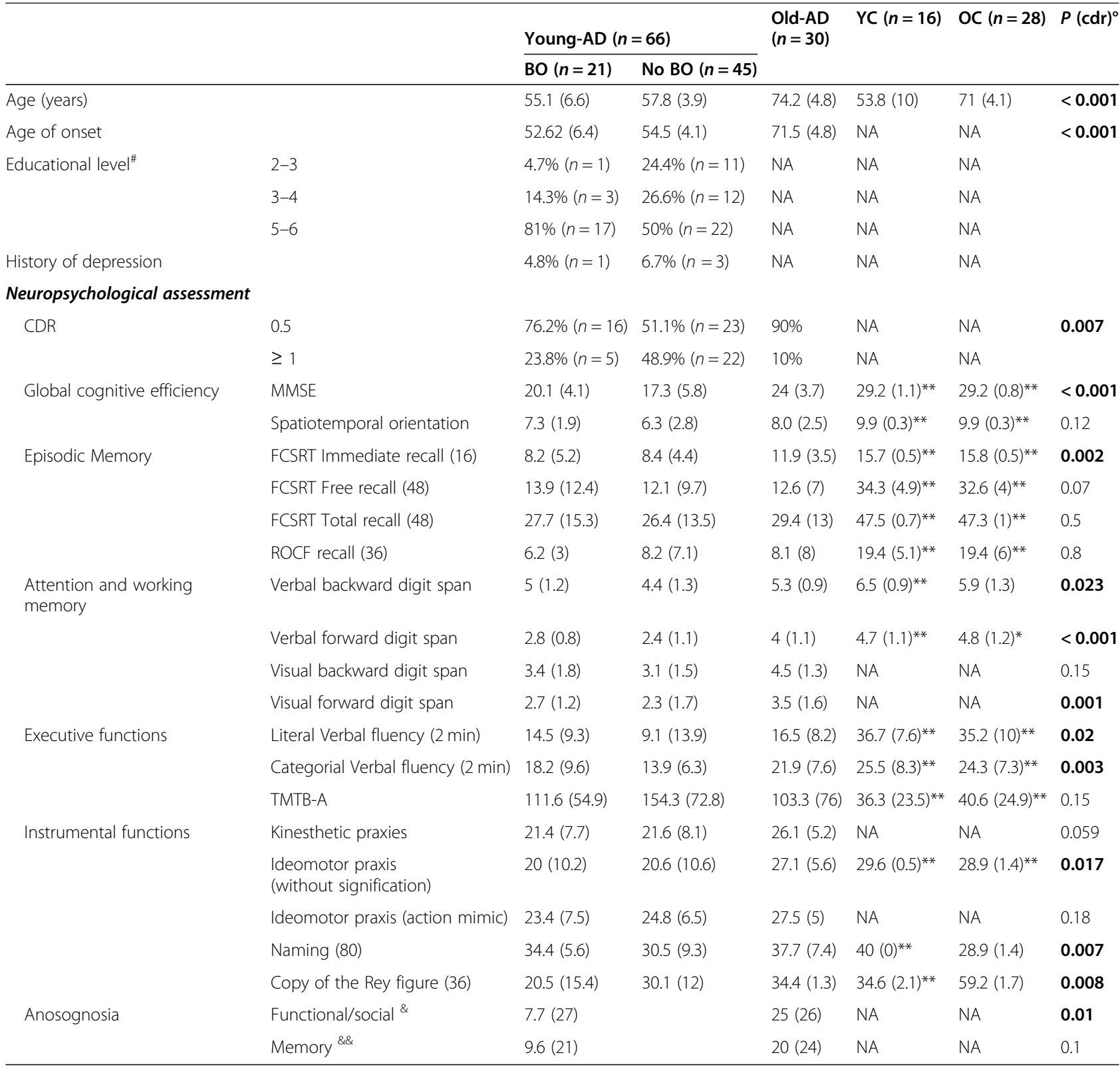

Data are mean (SD). ${ }^{*} p<0.05$ and ${ }^{* *} p<0.001$, in comparison with controls

$p$ (cdr) ${ }^{\circ}$ comparison between young-AD and old-AD adjusted with CDR score

With Prof. act.: with professional activity

CDR Clinical Dementia Rating Scale, FCSRT Free and Cued Selective Reminding test, ROCF Rey-Osterrieth Complex Figure, TMT Trail Making test (A and B)

"Educational level was quoted as follows: 1, no diploma; 2-3, 5 years of scholarship; 4-5, from 9 to 12 years of education; 6-7, more than 12 years of education

${ }^{\&}$ Difference between the score of the Cambridge Battery Inventory (CBI) assessed by the caregiver and by the patient. ${ }^{8 \&}$ Difference between the score of the Mac Nair scale assessed by the caregiver and by the patient

\section{Limitations}

The present study has some limitations, particularly its retrospective nature. This is however inherent to the data studied, which can only be collected retrospectively. In order to limit selection bias, the patient's initial complaint was collected by two neurologists blind to each other, whose interpretations were all congruent.

\section{Conclusions}

Early symptoms like occupational burnout-like syndrome could be under-recognized in young-AD and could possibly be underlain by a working memory deficit. It is crucial to consider and further study these early symptoms to avoid delayed diagnosis, which often impacts the quality of patients' care and compromises their 
chances of participating in therapeutic trials, due to already advanced cognitive and functional alteration at the time of diagnosis.

\section{Abbreviations}

AD: Alzheimer's disease; CSF: Cerebrospinal fluid; CDR: Clinical Dementia Rating

\section{Acknowledgements}

Not applicable.

\section{Authors' contributions}

$\mathrm{VH}$ and EGG participated in data acquisition. PO and LH analyzed the data and drafted the manuscript for intellectual content. MS and $\mathrm{JL}$ designed and conceptualized study, analyzed the data and drafted the manuscript for intellectual content. CRJ interpreted the data and revised the manuscript for intellectual content. All authors read and approved the final version of the manuscript.

\section{Funding}

This research received specific grant from funding agencies in the public, commercial, or not-for-profit sectors. Imabio study : French Health Ministry (PHRC) under reference PHRC- 0054-N 2010 and Institut Roche de Recherche et Medecine Translationelle. Shatau7-Imatau: French Ministry of Health grant (PHRC-2013-0919), CEA, Fondation pour la recherche sur Alzheimer, Institut de Recherches Internationales Servier, France-Alzheimer.

\section{Availability of data and materials}

The dataset used during the current study is available from the corresponding author on reasonable request.

\section{Declarations}

\section{Ethics approval and consent to participate}

In accordance with the French legislation, patients for whom clinical and CSF data were generated during routine clinical workup and their relatives were informed that individual data could be used in clinical research studies and they signed a specific consent form (MA-D20-R56 study).

\section{Consent for publication}

Not applicable.

\section{Competing interests}

The authors declare that they have no competing interests.

\section{Author details}

'Department of Neurology of Memory and Language, GHU Paris Psychiatry and Neurosciences, Hôpital Sainte Anne, 1 rue Cabanis, F-75014 Paris, France. ${ }^{2}$ Université de Paris, F-75006 Paris, France. ${ }^{3}$ Université Paris-Saclay, BioMaps, CEA, CNRS, Inserm, F-91401 Orsay, France.

Received: 26 December 2020 Accepted: 12 April 2021

Published online: 29 April 2021

\section{References}

1. Mendez MF. Early-onset Alzheimer disease. Neurol Clin. 2017;35(2):263-81. https://doi.org/10.1016/j.ncl.2017.01.005.

2. Koedam ELGE, Lauffer $V$, van der Vlies AE, van der Flier WM, Scheltens $P$, Pijnenburg YAL. Early-versus late-onset Alzheimer's disease: more than age alone. J Alzheimers Dis JAD. 2010;19(4):1401-8. https://doi.org/10.3233/JA D-2010-1337.

3. Hamelin L, Bertoux M, Bottlaender M, Corne H, Lagarde J, Hahn V, et al. Sulcal morphology as a new imaging marker for the diagnosis of early onset Alzheimer's disease. Neurobiol Aging. 2015;36(11):2932-9. https://doi. org/10.1016/..neurobiolaging.2015.04.019.

4. Ossenkoppele R, Cohn-Sheehy BI, La Joie R, Vogel JW, Möller C, Lehmann $M$, et al. Atrophy patterns in early clinical stages across distinct phenotypes of Alzheimer's disease. Hum Brain Mapp. 2015;36(11):4421-37. https://doi. org/10.1002/hbm.22927.

5. Schöll M, Ossenkoppele R, Strandberg O, Palmqvist S, Swedish BioFINDER study, Jögi J, et al. Distinct 18F-AV-1451 tau PET retention patterns in early- and late-onset Alzheimer's disease. Brain J Neurol 2017;140:2286-2294, 9, doi: https://doi.org/10.1093/brain/awx171.

6. WHO. World Health Organisation, 2019. Burn-out an "occupational phenomenon": international classification of Diseases. 2019. Retrieved from. https://www.who.int/mental_health/\%20evidence/burn-out/en/. 2019.

7. Wear HJ, Wedderburn CJ, Mioshi E, Williams-Gray CH, Mason SL, Barker RA, et al. The Cambridge Behavioural Inventory revised. Dement Neuropsychol. 2008;2(2):102-7. https://doi.org/10.1590/S1980-57642009DN20200005.

8. Dubois B, Feldman $\mathrm{HH}$, Jacova $\mathrm{C}$, Hampel $\mathrm{H}$, Molinuevo JL, Blennow $\mathrm{K}$, et al. Advancing research diagnostic criteria for Alzheimer's disease: the IWG-2 criteria. Lancet Neurol. 2014;13(6):614-29. https://doi.org/10.1016/S14 74-4422(14)70090-0.

9. Ross SJ, Graham N, Stuart-Green L, Prins M, Xuereb J, Patterson K, et al. Progressive biparietal atrophy: an atypical presentation of Alzheimer's disease. J Neurol Neurosurg Psychiatry. 1996;61(4):388-95. https://doi.org/1 $0.1136 /$ jnnp.61.4.388

10. Gorno-Tempini ML, Hillis AE, Weintraub S, Kertesz A, Mendez M, Cappa SF, et al. Classification of primary progressive aphasia and its variants. Neurology. 2011;76(11):1006-14. https://doi.org/10.1212/WNL.0b013e31 821103 e6.

11. Benson DF, Davis RJ, Snyder BD. Posterior cortical atrophy. Arch Neurol. 1988:45(7):789-93. https://doi.org/10.1001/archneur.1988.00520310107024.

12. Crutch SJ, Schott JM, Rabinovici GD, Murray M, Snowden JS, van der Flier WM, et al. Consensus classification of posterior cortical atrophy. Alzheimers Dement J Alzheimers Assoc. 2017;13(8):870-84. https://doi.org/10.1016/j.ja Iz.2017.01.014.

13. van Vliet D, de Vugt ME, Bakker C, YAL P, MJFJ V-D, RTCM K, et al. Time to diagnosis in young-onset dementia as compared with late-onset dementia. Psychol Med. 2013;43:423-32.

14. Kim EJ, Cho SS, Jeong Y, Park KC, Kang SJ, Kang E, et al. Glucose metabolism in early onset versus late onset Alzheimer's disease: an SPM analysis of 120 patients. Brain J Neurol. 2005;128(8):1790-801. https://doi. org/10.1093/brain/awh539.

15. Gour N, Felician O, Didic M, Koric L, Gueriot C, Chanoine V, et al. Functional connectivity changes differ in early and late-onset Alzheimer's disease. Hum Brain Mapp. 2014;35(7):2978-94. https://doi.org/10.1002/hbm.22379.

16. Neufang S, Akhrif A, Riedl V, Förstl H, Kurz A, Zimmer C, et al. Disconnection of frontal and parietal areas contributes to impaired attention in very early Alzheimer's disease. J Alzheimers Dis JAD. 2011;25(2):309-21. https://doi. org/10.3233/JAD-2011-102154.

17. Brier MR, Thomas JB, Fagan AM, Hassenstab J, Holtzman DM, Benzinger TL, et al. Functional connectivity and graph theory in preclinical Alzheimer's disease. Neurobiol Aging. 2014;35(4):757-68. https://doi.org/10.1016/j. neurobiolaging.2013.10.081.

\section{Publisher's Note}

Springer Nature remains neutral with regard to jurisdictional claims in published maps and institutional affiliations.
Ready to submit your research? Choose BMC and benefit from:

- fast, convenient online submission

- thorough peer review by experienced researchers in your field

- rapid publication on acceptance

- support for research data, including large and complex data types

- gold Open Access which fosters wider collaboration and increased citations

- maximum visibility for your research: over $100 \mathrm{M}$ website views per year

At BMC, research is always in progress.

Learn more biomedcentral.com/submissions 